\title{
OS ÍNDICES IGC, ENADE E CAPES NOS CURSOS DE ADMINISTRAÇÃO
}

\author{
MARIA ANDRÉA ROCHA ESCOBAR \\ MICHAEL SAMIR DALFOVO \\ MIGUEL ANGEL VERDINELLI
}

\begin{abstract}
RESUMO
Recentemente foi criado o Índice Geral de Curso (IGC) que avalia as instituições de uma maneira geral. Esse índice é gerado a partir de uma série de outros índices, bem como ENADE e CAPES. A utilização do índice poderá auxiliar gestores de IES e coordenadores de cursos como suporte para tomadas de decisão. Nesse sentido, o presente estudo teve como objetivo avaliar a similitude existente entre os índices de avaliação IGC, ENADE e CAPES dos cursos de administração. O curso de administração foi escolhido pela familiaridade dos autores com a área. A pesquisa desenvolvida foi de caráter exploratório, a partir de dados secundários que permitiram gerar uma tabela para 51 IES. A técnica estatística utilizada foi a Análise de Correspondência Múltipla. Os resultados demonstram que os cursos de administração corroboram com as notas altas do IGC. O destaque é para as regiões Sul e Sudeste, bem como para programas de pós-graduação em nível de mestrado, acadêmico e profissional, e doutorado, principalmente nas universidades federais. Conclui-se que este estudo poderá auxiliar gestores a refletir e relacionar o IGC com os cursos oferecidos de forma a buscar excelência, além de auxiliá-los a manter um mapeamento dos concorrentes.
\end{abstract}

PALAVRAS-ChAVE: IGC. ENADE. CAPES. Avaliação institucional. Ensino de administração. 


\section{INTRODUÇÃO}

Através da Portaria n. 11, de 28 de abril de 2003, do MEC/SESu ${ }^{1}$ foi instituída uma comissão especial com o objetivo de analisar, oferecer subsídios, fazer recomendações, propor critérios e estratégias para a reformulação dos processos de avaliação da educação superior (BRASIL, 2003). Essa comissão fundamentou sua atividade numa visão mais ampla de avaliação.

O SINAES ${ }^{1}$ encontra-se em fase de reformulação ou reestruturação desde a sua implementação. Os critérios estabelecidos para avaliação, tantos dos cursos como das IES ${ }^{1}$, agem no sentido de regulação. São estabelecidos indicadores como o $\operatorname{ENADE}^{1}, \operatorname{IDD}^{1}$ e as variáveis de insumos que compõem os $\mathrm{CPC}^{1}$. Sobre o ENADE, reflete-se na avaliação do desempenho estudantil em um comparativo ingresso e concluintes, que podem auxiliar os cursos de graduação sobre possíveis melhorias na qualidade de ensino.

Alguns indicadores recentes foram instituídos, como é o caso do IGC, pela portaria $\mathrm{n}$. 12 , de 05 de setembro de 2008, que correlaciona a avaliação da IES, em uma perspectiva sobre os cursos de graduação e seus indicadores, com a pós-graduação em nível stricto sensu avaliada pela CAPES $^{1}$ (BRASIL, 2008a). Nesse sentido, percebe-se uma preocupação com uma avaliação unificada sobre os diversos níveis de ensino. Tanto é, que há estudos como de Barreyro (2008), Sguissardi (2008) e Polidori (2009) que sugerem uma reflexão sobre a validade desses indicadores, incluindo o $\mathrm{IGC}^{1}$. Os estudos que abordam tal crítica comentam sobre a dualidade existente entre indicadores terem a função de ranqueamento, não para fins de qualidade, mas sim para objetivar a mercantilização dos cursos e suas respectivas IES. O foco do presente estudo não está em adotar o posicionamento de crítica sobre os indicadores, bem como de seus índices.

Acredita-se que os gestores de IES e seus respectivos coordenadores de curso possam se utilizar dos indicadores para auto-avaliação e comparação com demais concorrentes. Entretanto, seria interessante conseguir manter relações de análise sobre os índices de avaliação. Nesse sentido, o objetivo do presente estudo está em avaliar a similitude existente entre os índices de avaliação IGC, ENADE e CAPES dos cursos de administração.

A estrutura deste trabalho contempla, a seguir, no tópico 2, descrição dos sistemas de avaliação IGC, ENADE e CAPES. Já no tópico 3, são delineados os procedimentos metodológicos adotados a partir dos dados secundários; e são apresentados, no tópico 4, os resultados. Finalmente, apresentam-se as considerações finais e referências (tópico 5 e 6).

\section{DESCRIÇÃO DOS SISTEMAS DE AVALIAÇÃO}

\subsection{ENTENDENDO O ÍNDICE GERAL DE CURSOS (IGC) E O EXAME NACIONAL DE DESEMPENHO (ENADE)}

A avaliação da Educação Superior é um tema que já aparece na década de 80 . Entretanto, seu marco representativo se consolidou com a promulgação da Lei n. 10.861, de 14 de abril de 2004, que instituiu o modelo SINAES, o qual tem a finalidade de viabilizar o acompanhamento da evolução da educação superior (BRASIL, 2004). O SINAES assente que o $\mathrm{MEC}^{1}$ norteie o processo de autorização, reconhecimento e renovação dos cursos de

\footnotetext{
${ }^{1}$ Vide Anexo a Lista de Acrônimos
} 
graduação. O foco implícito nesse novo sistema consistia em instalar um ciclo de avaliação que seria referencial para a regulação das instituições (POLIDORI, 2009).

Em consonância com a n. Lei 10.861, o SINAES ao instaurar a avaliação deve contribuir para integrar a análise das diversas dimensões e instrumentos com foco numa concepção global; possibilitar a correlação da avaliação com os fundamentos e a política de educação superior; permitir avaliação interna e externa; como também a avaliação das condições do ENADE.

O objetivo do SINAES é assegurar o processo nacional de avaliação da IES, de cursos de graduação e do desempenho acadêmico dos estudantes, buscando a melhoria da qualidade do ensino superior no país (INEP, 2009). De acordo com Polidori (2009), os resultados da avaliação devem dar suporte aos processos de regulação e supervisão da educação superior que compreendem as ações de autorização, reconhecimento e renovação de reconhecimento de cursos de graduação, e credenciamento e recredenciamento de IES.

O SINAES é tido como uma política de Estado, que tem como princípio norteador a regulação e a emancipação. Por ter aspectos tanto de avaliação emancipatória, preservados do documento da $\mathrm{CEA}^{1}$ e, que são análogos aos princípios do $\mathrm{PAIUB}^{1}$, quanto de aspectos da avaliação regulatória, percebidos na Lei que o criou, se constitui como um sistema misto.

Estruturalmente, o SINAES, pode ser dividido em três grandes pilares:

a) avaliação institucional, com o propósito de identificar seu perfil e o significado da sua atuação, por meio de suas atividades, cursos, programas, projetos e setores, respeitando a diversidade e as especificidades das diferentes organizações acadêmicas;

b) avaliação dos cursos de graduação, no qual procura-se identificar as condições do ensino oferecidos aos estudantes, perfil do corpo docente, instalações físicas e organização didático-pedagógica;

c) ENADE, em que se mensura o desempenho dos estudantes em relação aos conteúdos programáticos previstos nas diretrizes curriculares do respectivo curso, suas habilidades ao que diz respeito às exigências da evolução do conhecimento e suas competências de assimilar questões ligadas à esfera específica de sua profissão, a realidade brasileira e a outras áreas de conhecimento. Esse exame será realizado por procedimentos amostrais, com uma periodicidade trienal. (INEP, 2009).

Recentemente, o Ministério da Educação fez aflorar dois novos indicadores no contexto da educação brasileira. O primeiro foi instituído através da portaria normativa n. 04 , de 05 de setembro de 2008, denominado de CPC, sendo um instrumento de avaliação para renovação dos cursos de graduação. O CPC tem como bases: a) o conceito do ENADE que lhe é atribuído, correspondente a $40 \%$ da nota; b) o conceito do IDD, responsável por fornecer informações acerca do montante que a instituição agregou ao estudante, representando 30\% da nota final; e c) as Variáveis de Insumo, que correspondem a 30\% da nota final. Sendo esses integrados por corpo docente, considerando-se a titulação, atribuindo-lhe peso de $10,2 \%$, e o regime de trabalho $23,8 \%$, infra-estrutura e instalações físicas, com peso de $38,9 \%$ e programa didático-pedagógico com 27,2\% do peso (INEP, 2009a).

Tais conceitos recebem pontuação de um a cinco, segundo critérios do INEP $^{1}$. Os cursos que obtiverem conceito 1 e 2 serão considerados inaptos e receberão, obrigatoriamente, a visita da comissão de avaliação. Para os cursos que apresentarem conceitos três e quatro, a visita será opcional e os cursos com conceito cinco obterão o status de curso de referência e terão suas portarias de renovação de reconhecimento lançadas automaticamente pela SESu. (POLIDORI, 2009). 
O ENADE preocupa-se em aferir o rendimento dos estudantes dos cursos de graduação em relação aos conteúdos previstos nas diretrizes curriculares dos respectivos cursos com as suas habilidades, competência, enfim, com a sua formação como um todo, sendo formalmente instituído no Brasil, por meio da Lei n. 10.861/2004, consistindo em um dos componentes do Sistema Nacional de Avaliação da Educação Superior. O ENADE é realizado por amostragem de estudantes definida pelo INEP, identificados como ingressantes (primeiro ano do curso) e concluintes (último ano do curso), sendo aplicadas duas provas, uma ao final do primeiro ano e outra, no último ano de curso, além da prova são utilizados outros instrumentos de avaliação como um questionário que mensura a impressão que tiveram sobre a prova, um questionário socioeconômico, questionário do coordenador do curso. (INEP, 2009b).

O segundo indicador criado é o novo IGC, estabelecido pela Portaria Normativa n. 12, de 05 de setembro de 2008, tendo como objetivo ser um indicador de qualidade das IES no Brasil, o qual estabelece informações consoantes aos cursos superiores constantes dos cadastros, censos e avaliações oficiais, disponíveis no INEP e na CAPES. Conforme a Portaria Normativa supracitada, em seu artigo $2^{\circ}$, incisos I e II, esse índice é construído com base numa média ponderada das notas dos CPC, sendo a ponderação determinada pelo número de matrículas em cada um dos cursos de graduação correspondentes e da média ponderada das notas dos programas de pós-graduação, obtidas a partir da conversão dos conceitos fixados pela CAPES, sendo a ponderação baseada no número de matrículas em cada um dos cursos ou programas de Pós-Graduação stricto sensu correspondentes. A Portaria demonstra nos dois primeiros parágrafos do artigo $2^{\circ}$ que a ponderação levará em conta a distribuição dos alunos da IES entre os diferentes níveis de ensino (graduação, mestrado e doutorado) (BRASIL, 2008a). O IGC de cada Instituição de Ensino Superior no país é divulgado anualmente pelo INEP/MEC.

\subsection{COORDENAÇÃO DE APERFEIÇOAMENTO DE PESSOAL DE NÍVEL SUPERIOR (CAPES)}

Em 11 de julho de 1951, a Campanha Nacional de Aperfeiçoamento de Pessoal de Nível Superior (atual CAPES) foi criada por meio do Decreto 29.471, da Presidência da República, com a finalidade de elaborar e executar a política de pós-graduação no país. Na década de 70, esta se torna de fundamental importância na implantação da pós-graduação no Brasil, e na mesma década começa a realizar a avaliação. Atualmente, a avaliação abrange os programas com cursos de mestrado profissional, mestrado acadêmico e doutorado - nível stricto senso. (MEC, 2004).

O sistema de avaliação CAPES passou por várias reformulações em diferentes momentos de sua história, sendo que sua origem se deu devido à necessidade de avaliar os discentes de pós-graduação para o que diz respeito à distribuição de bolsas, pois de acordo com Córdova (1996), em sua criação a CAPES tinha por princípio assegurar a existência de pessoal especializado em quantidade e qualidade suficientes para atender às necessidades dos empreendimentos públicos e privados que visam ao desenvolvimento socioeconômico do país. Conforme Neves (1996), cabia à Capes [...] "prover o país de recursos humanos qualificados, capazes de garantir o sucesso das grandes iniciativas de investimentos públicos e privados, que viria a transformar a sociedade brasileira em geral".

Atualmente, a CAPES configura-se como a principal agência do sistema nacional de Pós-Graduação passando a fundamentar o MEC na formulação de políticas e intensificar o desenvolvimento dos cursos desses níveis no país, através de incentivos visando à qualificação de recursos humanos para docência e pesquisa no intuito de atender a demanda dos setores públicos e privados. A CAPES se utiliza de instrumentos denominados de 
programas, a fim de atender aos objetivos de sua origem, sustentado pela orientação básica de corroborar a implantação e o desenvolvimento dos programas de Pós-Graduação stricto senso, oferecer bolsas de estudos aos pós-graduandos e promover a avaliação dos cursos em nível de mestrado e doutorado ofertado no país, sendo também instituído para atender as necessidades emergentes institucionais. (SOUZA; PEREIRA, 2002).

A sistemática de avaliação apresenta-se em dois momentos. O primeiro compreendido entre o período de 1976 a 1996, o qual atribuía conceito final aos cursos numa escala decrescente de $\mathrm{A}$ a $\mathrm{E}$, definindo desta forma três categorias de cursos:

a) consolidados apresentados $\mathrm{A}$ e $\mathrm{B}$;

b) em consolidação com conceitos $\mathrm{C}$;

c) os deficientes, cujos conceitos eram D ou E.

Ressalta-se que esta última categoria não era reconhecida. $\mathrm{O}$ sistema de avaliação que estava sendo adotado passou a emitir nítidos sinais de esgotamento ao não discriminar mais a qualidade acadêmica entre os programas.

No segundo momento, o processo de avaliação da CAPES passou a atribuir conceitos aos programas a partir de 1998. Esses conceitos podem variar de uma escala crescente de 1 a 7, sendo que a nota 3 passa a ser referenciada como padrão mínimo e a nota 5, a máxima para o curso de mestrado. No entanto, para o doutorado, a nota mínima seria 4 e a máxima 7. Os programas com conceitos 1 e 2 não são reconhecidos e os programas com conceitos 6 ou 7 são tidos como programas de excelência. De acordo com a CAPES (2009), esse fato ocorreu devido à opção de se adotar padrões internacionais de qualidade, como característica para avaliação dos programas nacionais de excelência.

O sistema de avaliação da CAPES (2009) engloba dois processos. O primeiro processo é a Avaliação dos Programas de Pós-Graduação, em que há o acompanhamento anual e finalizado com a avaliação trienal do desempenho de todos os cursos e programa que compõe o SNPG. Os resultados desse processo, definido pela conferência de um conceito na escala de 1 a 7 sustenta a deliberação CNE/MEC sobre quais cursos e/ou programas obterão a renovação de "reconhecimento, a vigorar no triênio subseqüente. Os programas que obtiverem conceito inferior a 3 serão descredenciados do sistema. Evidencia-se que o acompanhamento do curso não acarreta atribuição de conceitos ao programa, no entanto, subsidia na identificação de possíveis desvios de desempenho nos cursos avaliados.

O segundo processo é a Avaliação das Propostas de Cursos Novos de Pós-Graduação, que faz parte da norma estabelecida para a admissão de novos programas e cursos ao SNPG. Ao avaliar as propostas de cursos novos, a CAPES verifica a qualidade de tais propostas e se elas atendem ao padrão de qualidade requerido desse nível de formação e encaminha os resultados desse processo para, nos termos da legislação vigente, fundamentar a deliberação do CNE/MEC sobre o reconhecimento de tais cursos e sua incorporação ao SNPG. Os dois processos - avaliação dos programas de Pós-Graduação e avaliação das propostas de novos programas e cursos - são alicerçados em um mesmo conjunto de princípios, diretrizes e normas, compondo, assim, um só Sistema de Avaliação (CAPES, 2009).

A CAPES buscou reorganizar seus objetivos, focando mais no cumprimento dos padrões de qualidade e na sistematização da pós-graduação, através de um forte e elaborado sistema de avaliação:

a) estabelecer o padrão de qualidade exigido dos cursos de mestrado e de doutorado e identificar os cursos que atendem a tal padrão;

b) fundamentar, nos termos da legislação em vigor, os pareceres do Conselho Nacional de Educação sobre autorização, reconhecimento e renovação de reconhecimento dos cursos de mestrado e doutorado brasileiros - exigência legal para que estes possam expedir diplomas com validade nacional reconhecida pelo Ministério da Educação, MEC; 
c) impulsionar a evolução de todo o Sistema Nacional de Pós-Graduação, SNPG, e de cada programa em particular, antepondo-lhes metas e desafios que expressam os avanços da ciência e tecnologia na atualidade e o aumento da competência nacional nesse campo;

d) contribuir para o aprimoramento de cada programa de Pós-Graduação, assegurando-lhe o parecer criterioso de uma comissão de consultores sobre os pontos fracos e fortes de seu projeto e de seu desempenho e uma referência sobre o estágio de desenvolvimento em que se encontra;

e) contribuir para o aumento da eficiência dos programas no atendimento das necessidades nacionais e regionais de formação de recursos humanos de alto nível;

f) dotar o país de um eficiente banco de dados sobre a situação e evolução da Pós-Graduação; (CAPES, 2009).

Dessa forma, a CAPES procurou desempenhar sua atividade de desenvolver a pósgraduação e a pesquisa científica e tecnológica no país.

\section{METODOLOGIA}

A presente pesquisa é caracterizada como do tipo exploratória e os dados utilizados são de fontes secundárias: INEP (2009) e CAPES (2009). A partir da tabela do IGC (INEP, 2009), foram selecionadas as IES que possuíam cursos de graduação e pós-graduação em nível stricto sensu em administração. Em um segundo momento, foram adicionados os índices do último ENADE do respectivo curso, referente ao ano de 2006, e CAPES (2009). Vale ressaltar que da análise foram descartadas 11 IES que não constavam na Tabela do IGC (INEP, 2009). Assim, criou-se a Tabela 1 com uma amostra de 51 IES que atendiam a esses requisitos e que se apresenta abaixo, resumidamente, por ordem alfabética:

Tabela 01 - IGC, ENADE, CAPES das IES com cursos de Administração.

\begin{tabular}{|l|l|l|l|l|l|c|c|l|l|}
\hline Casos & Nome & IES & UF & Região & Tipo & IGC & ENADE & Nível & CAPES \\
\hline 01 & FACCAMP & Fac. & SP & Sudeste & PRIVADA & 3 & E-3 & f & C-3 \\
\hline 02 & FEAD & Fac. & MG & Sudeste & PRIVADA & 3 & E-2 & f & C-3 \\
\hline Continua ... & $\ldots$ & $\ldots$ & $\ldots$ & $\ldots$ & $\ldots$ & $\ldots$ & $\ldots$ & $\ldots$ & $\ldots$ \\
\hline 51 & USCS & Univ & SP & Sudeste & MUNICIPAL & 3 & E-3 & md & C-4 \\
\hline
\end{tabular}

Fonte: A partir do INEP (2009) e CAPES (2009)

A Tabela 1 apresenta as seguintes variáveis:

a) variável nome - Siglas das 51 instituições avaliadas;

b) variável IES - Com categorias Faculdade, Centro-Universitário e Universidade;

c) variável UF - Com categorias das siglas das Unidades Federais do Brasil

d) região - Com categorias Sul, Sudeste, Centro-Oeste, Nordeste e Norte;

e) variável Tipo - Com categorias Privada, Federal, Estadual e Municipal;

f) IGC - Com conceitos 0, 1, 2, 3, 4 e 5;

g) ENADE - Com categorias E-2, E-3, E-4, E-5;

h) nível - Com categorias mestrado profissional (f), mestrado acadêmico (m) e doutorado $(\mathrm{d})$;

i) CAPES - Com categorias C-3, C-4, C-5, C-6.

Por se tratarem de variáveis qualitativas, optou-se pela técnica de análise de correspondência múltipla. Para tratar os dados, foi gerada a matriz no software Excel, posteriormente exportada para o software SPAD, em que foram descritos como variáveis ativas os índices IGC, ENADE, CAPES. Em seguida, foram acrescentadas as demais variáveis, caracterizadas no SPAD como ilustrativas, IES, UF, Região, Tipo e Nível. 
Os dados são apresentados por meio dos gráficos gerados pelo próprio software $S P A D$.

\section{RESULTADOS}

A análise partiu da técnica de correspondência múltipla por se tratar de variáveis qualitativas e por ter como objetivo geral avaliar a similitude existente entre os índices de avaliação IGC, ENADE e CAPES dos cursos de administração.

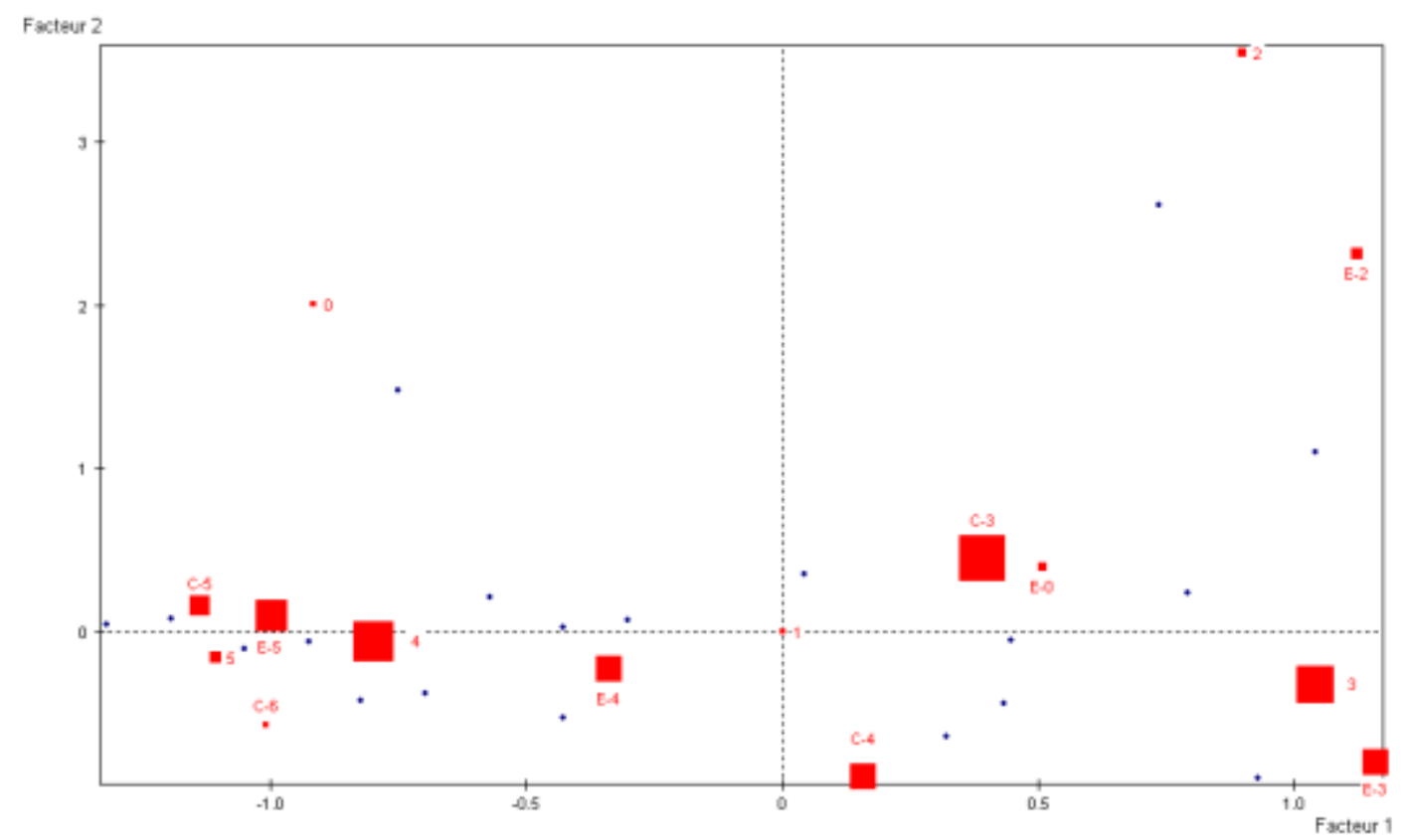

Gráfico 1: Cruzamento das variáveis IGC, ENADE e CAPES

Fonte: Gerados a partir dos dados tratados no SPAD (2009)

A partir do gráfico 1, percebe-se a similitude existente entre as variáveis IGC, ENADE e CAPES, em que as notas 2 do IGC e E-2 do ENADE em administração encontram-se próximas. Não houve ocorrências de nota 1 sobre o ENADE. Quanto à CAPES, as notas começaram a partir do conceito descrito como C-3 que é o mínimo considerado para que um curso em nível stricto-sensu possa ser recomendado. Assim como os conceitos 2 obtiveram certa semelhança e aproximação, o mesmo nota-se na curva sobre os índices 3, E-3, C-3. As que obtiveram nota 0 ou E-0 significam que não sofreram avaliação.

Destaca-se aqui que os agrupamentos mais perceptíveis referem-se aos conceitos do IGC 5, E-5, C-5 e C-6. Com isso, percebe-se que das 51 IES analisadas que possuem conceito IGC alto, os índices do ENADE e CAPES dos cursos de administração corroboram com o resultado final. Dados como esses podem ser considerados interessantes tanto do ponto de vista operacional e de melhorias das IES e seus cursos, como também para fins mercadológicos, conforme os vieses apresentados pelos estudos de Barreyro (2008), Sguissardi, (2008) e Polidori, (2009).

As figuras geométricas em forma de quadrados no gráfico 1 apresentam-se em tamanhos diferentes, pois é possível, a partir do software, identificar os índices que obtiveram maior expressividade ao peso relativo sobre cada conceito. Sendo assim, verificou-se uma maior concentração de IES que obtiveram conceitos 3 e 4 do IGC, C-3 da CAPES devido ao 
grande números de IES que possuem apenas mestrado, e E-5 do ENADE representando os cursos de administração.

Os pontos no gráfico representam as 51 IES que participaram disponibilizadas. Vale destacar que as IES que obtiveram índices semelhantes encontram-se sobrepostas no mesmo ponto. Ressalta-se aqui a menor quantidade de IES com cursos em administração com baixo índice. Por meio do corte horizontal, constatou-se uma maior incidência de pontos do lado esquerdo, que acompanha as notas mais altas tanto do IGC, como do ENADE e da CAPES. Dessa forma, foi possível averiguar que as IES analisadas que possuem cursos em administração apresentaram maiores valores nos conceitos do INEP e da CAPES. Além disso, infere-se que esse tipo de informação poderá auxiliar os gestores dos cursos de administração frente a outras IES.

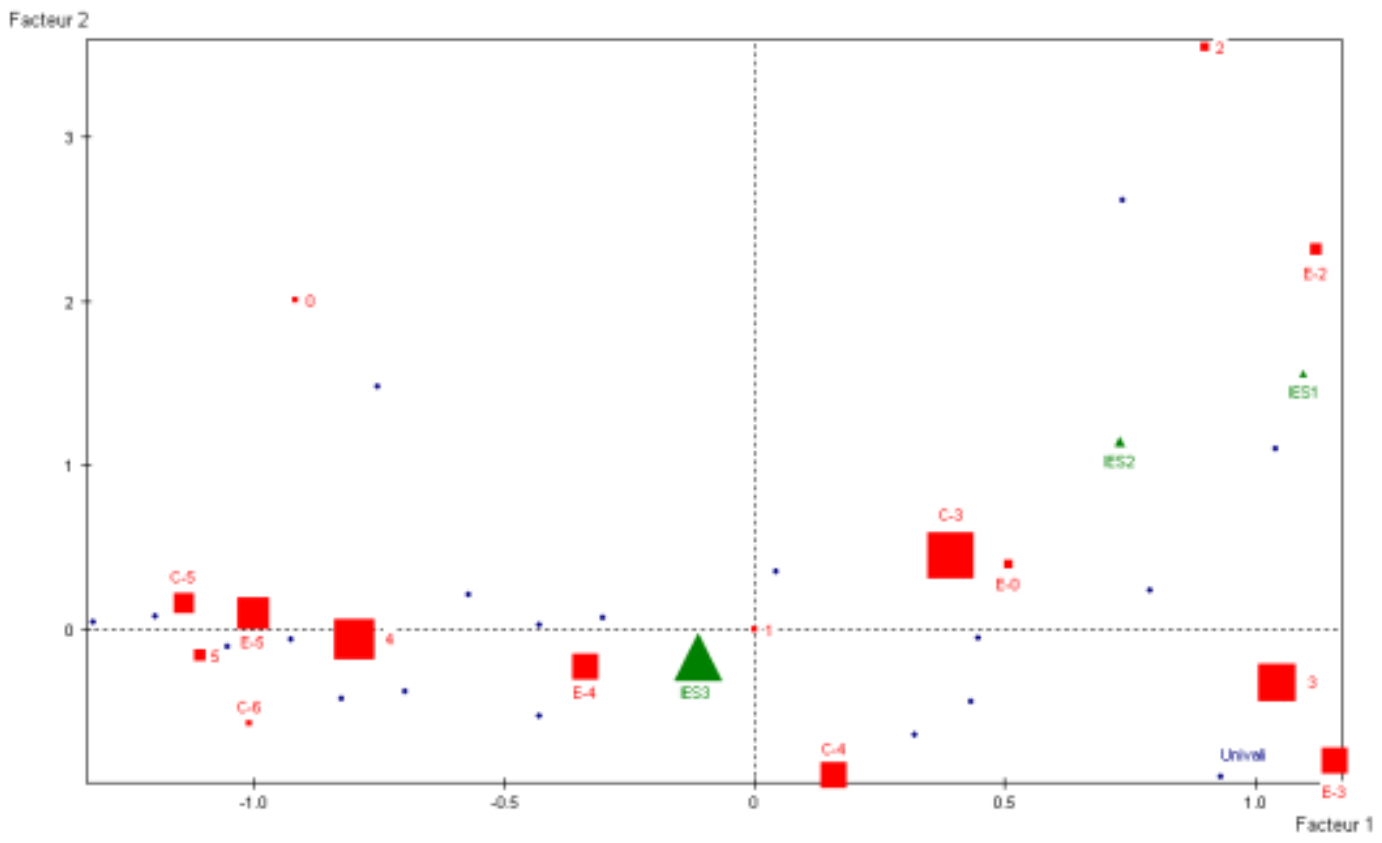

Gráfico 2: Cruzamento IGC, ENADE, CAPES x IES

Fonte: Gerados a partir do dados tratados no SPAD (2009)

Ao analisar as 51 IES, observa-se a maior incidência de universidades, sendo que apenas 4 IES são centros-universitários e 2 são faculdades. Comprovou-se esse dado, principalmente, pelo fato dos cursos em nível stricto-sensu estarem ligados às universidades. O gráfico 2 apresenta as IES com figuras geométricas em forma de triângulos. O triângulo IES1 representa as faculdades, o triângulo IES2 representa os centros-universitários e o triângulo IES3 representa as universidades. A variável IES foi tratada na correspondência múltipla como ilustrativa, não inferindo na ordem original dos índices, conforme já demonstrado no Gráfico 1.

Ficou evidenciado no Gráfico 2 que as IES3 (Universidades) são as que mais se aproximam dos maiores conceitos, principalmente do IGC 4 e 5, ENADE 4 e 5, e da CAPES 4, 5 e 6 . Do ponto de vista competitivo, um mapeamento como esse também é interessante por posicionar a IES de estudo frente às outras concorrentes. Esse panorama pode ser exemplificado com o ponto no canto inferior do lado do direito, representando a Universidade do Vale do Itajaí (UNIVALI), instituição ao qual pertencem os autores deste artigo. A IES em questão possui IGC 3, ENADE 3 e CAPES 4. Com isso, percebe-se que é interessante avaliar 
o ensino de graduação, visto que se encontra o índice E-4 em quadrante oposto ao que a IES em questão se encontra.

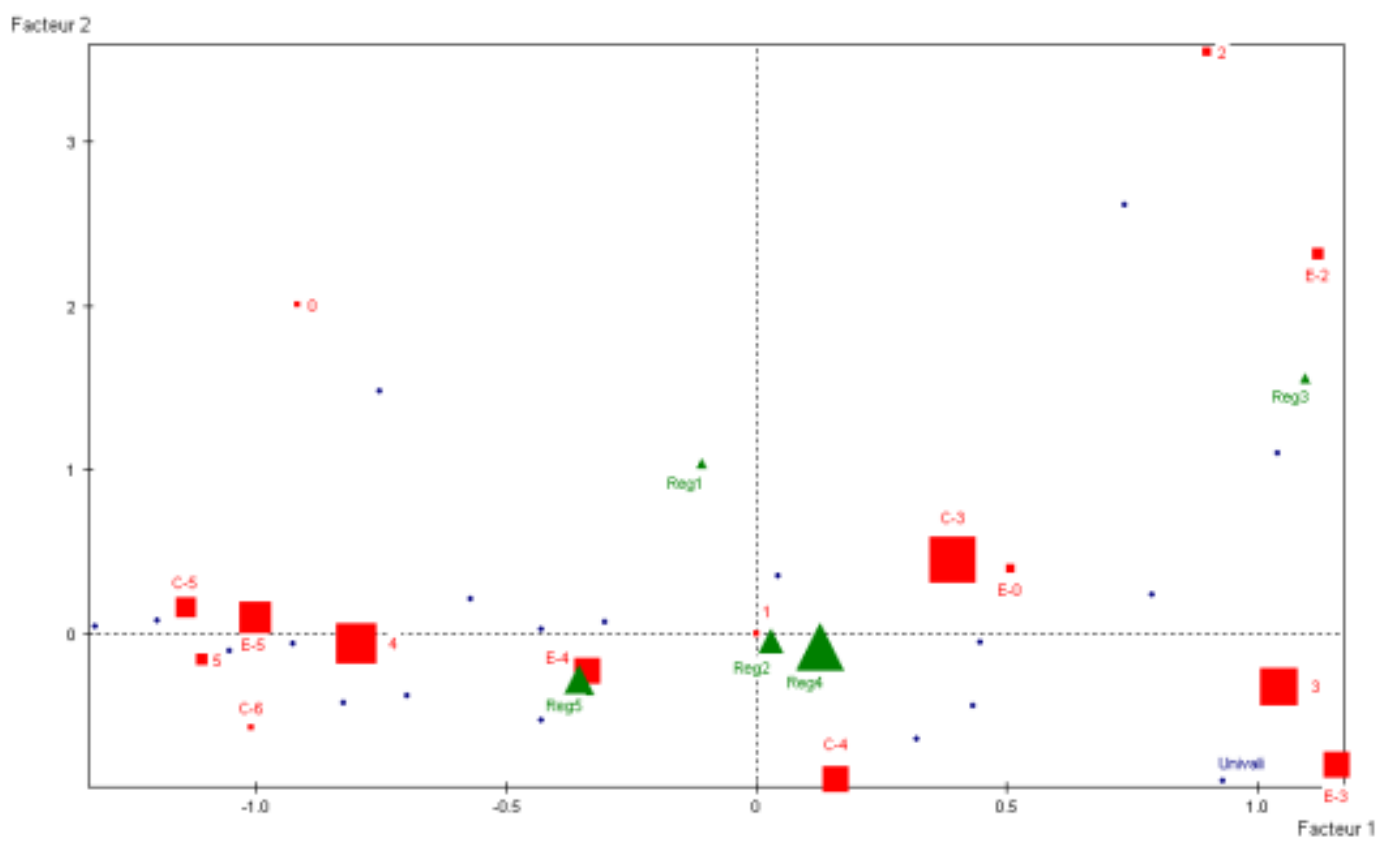

Gráfico 3: Cruzamento IGC, ENADE, CAPES x Região

Fonte: Gerados a partir do dados tratados no SPAD (2009)

Com o Gráfico 3, que trata da variável ilustrativa região, foram designadas as regiões Centro-Oeste como Reg1, Nordeste como Reg2, Norte como Reg3, Sudeste como Reg4, e Sul como Reg5. É possível observar pelos tamanhos das figuras geométricas que a maior incidência de IES analisadas foram as da região Sudeste. Destaca-se, pelos agrupamentos, que as IES que possuem maiores índices pertencem à Região Sul. Por outro lado, as que se encontram com índices mais baixos foram as IES do Norte.

Vale ressaltar, novamente, que o posicionamento das IES em suas regiões varia conforme as pontuações. Por exemplo, mesmo com incidência menor das IES pertencentes à região Nordeste, ela se posicionou próxima a Região Sudeste pelo fato de que há 2 IES (UFBA e UFPE) que possuem nota C-5.

Em uma visão mais específica por Unidade Federativa (UF), encontra-se o Gráfico 4, abaixo, em que os destaques vão para UF14 e UF4, os quais representam os Estados do Rio Grande do Sul e Espírito Santo, respectivamente. Os dois Estados são os que se aproximaram mais do agrupamento das maiores notas. Já o Estado que obteve menores índices é o Pará que se encontra localizado no canto superior direito do Gráfico 4.

As IES que demonstraram maior incidência pertencem aos Estados de São Paulo (UF16), Minas Gerais (UF5), Rio Grande do Sul (UF14), Santa Catarina (UF15) e Rio de Janeiro (UF11). 


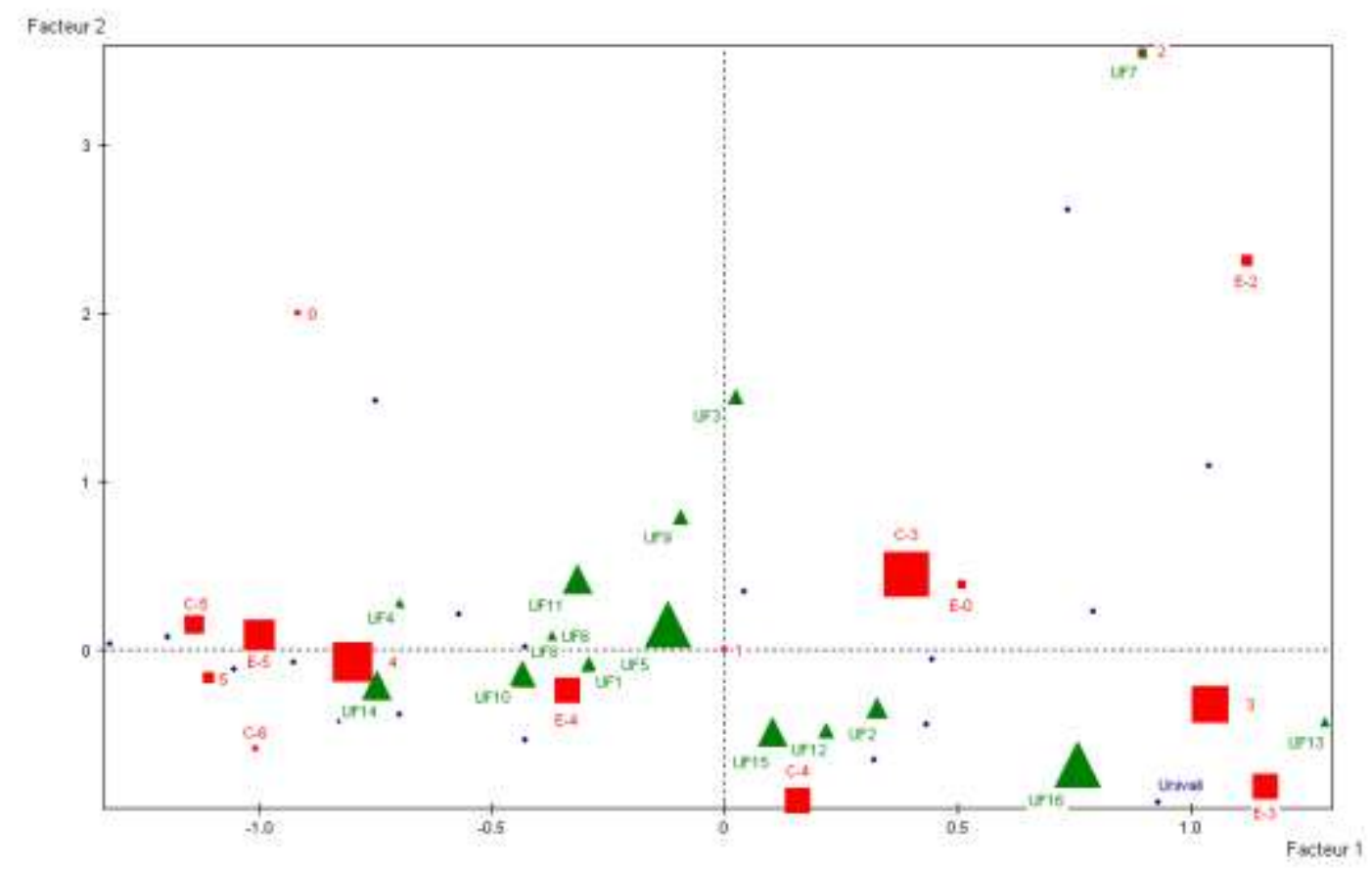

Gráfico 4: Cruzamento IGC, ENADE, CAPES x UF

Fonte: Gerados a partir do dados tratados no SPAD (2009)

Ao analisar o Gráfico 5, que retrata o tipo de instituição, sendo Tip1 para IES estaduais, Tip2 para IES federais, Tip3 para IES municipais, Tip4 para IES privadas. A maior quantidade de IES analisadas foram as federais e privadas. As IES que se encontram mais próximas aos agrupamentos foram as federais, seguidas das estaduais. Atenta-se aqui que as IES de caráter público possuem melhores índices do que as privadas.

Outro tipo de análise que pode ser encontrado no Gráfico 6 incluiu a variável Nível que se refere aos programas de nível Stricto Sensu caracterizando Niv1 como mestrado profissional, Niv2 como mestrado acadêmico, Niv3 como mestrado acadêmico e doutorado, Niv4 como mestrado acadêmico e profissional e doutorado e Niv5 como mestrado acadêmico e profissional.

A partir do Gráfico 6, foi possível verificar que grande parte das IES analisadas possui apenas pós-graduação em nível de mestrado, percebendo-se, dessa forma, o quanto ainda pode-se ampliar o número de pós-graduações em nível de doutoramento (Niv3 e Niv4). Ainda sobre o Gráfico 6, justifica-se que os Níveis 3 e 4 pelo menos deveriam obter conceito acima de 4 para serem recomendados pela CAPES. Notou-se que os cursos de pós-graduação em nível stricto sensu em administração corroboram com as altas notas das IES que possuíram IGC com conceitos 4 e 5. Esse tipo de análise permite perceber se a área de conhecimento de determinado curso possui similitude com os outros índices. Além disso, enfatiza-se uma similitude se cursos que possuem conceitos elevados em programas de pós-graduação (CAPES) seguem na mesma dinâmica com seus cursos de graduação (ENADE).

Os níveis que mais se aproximaram dos agrupamentos dos maiores índices foram os 5 que oferecem as três modalidades de ensino em nível stricto sensu e os 4 que oferecem mestrados acadêmico e profissional. Esse dado demonstrou-se interessante pelo fato de que as IES que apresentam mestrado e doutorado acadêmico e não-profissional (Niv3) ficaram em um terceiro nível. Por outro lado, as IES que oferecem apenas o curso de mestrado profissional (Niv1) foram as que se encontravam mais próximas dos menores índices. 


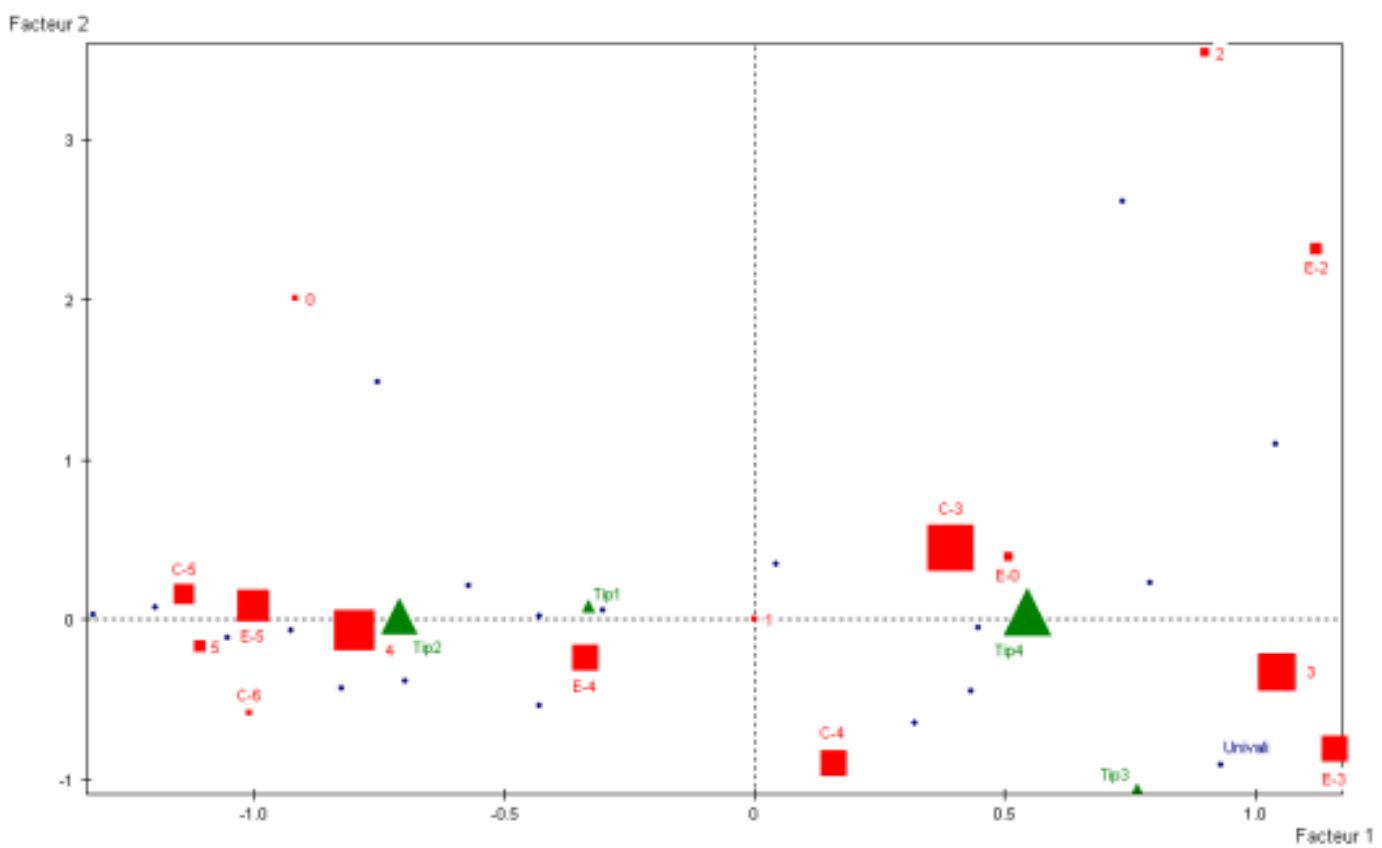

Gráfico 5: Cruzamento IGC, ENADE, CAPES x Tipo

Fonte: Gerados a partir do dados tratados no SPAD (2009)

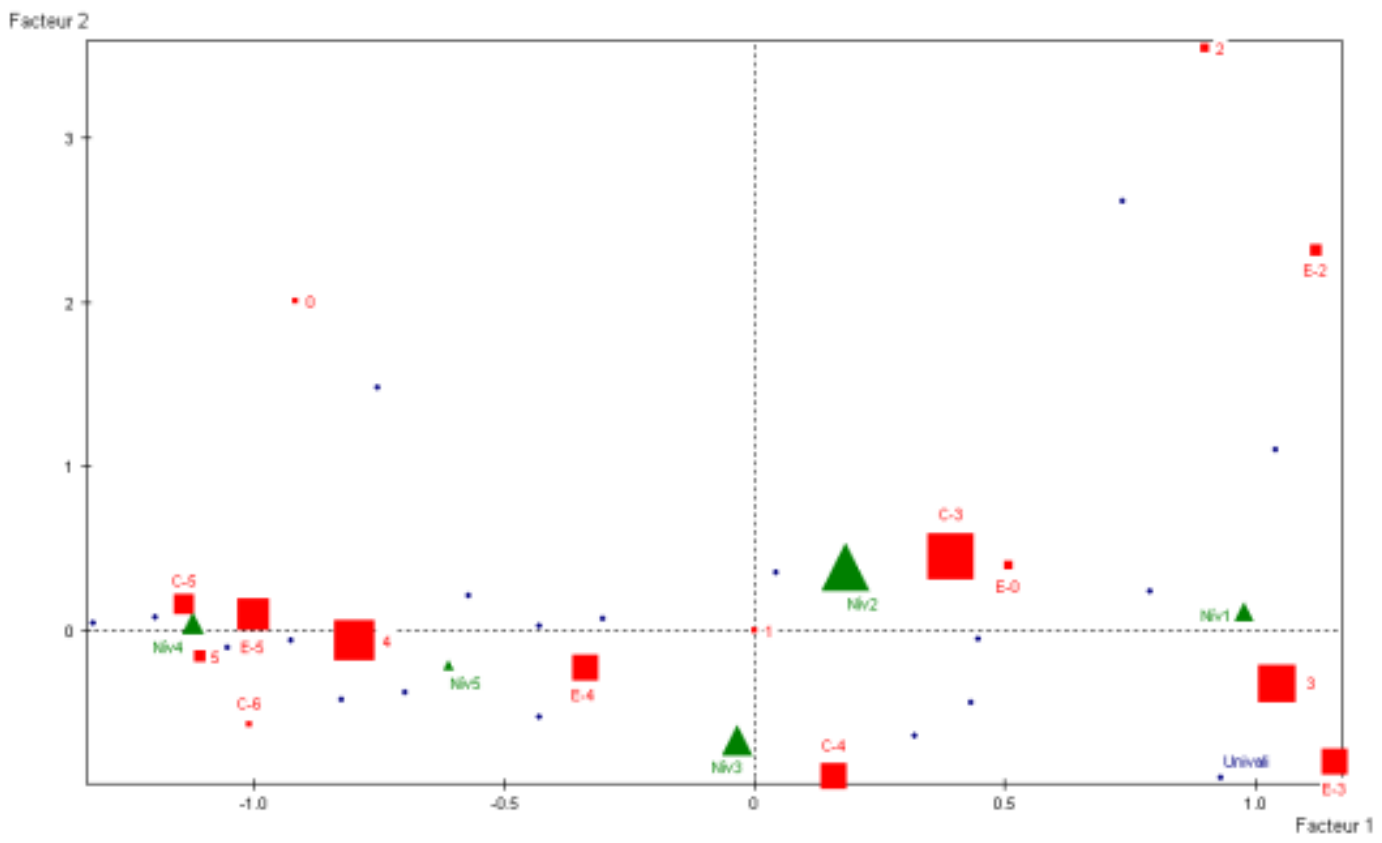

Gráfico 6: Cruzamento IGC, ENADE, CAPES x Nível

Fonte: Gerados a partir do dados tratados no SPAD (2009)

Um último cruzamento foi realizado e apresentado no Gráfico 7 tendo como variáveis ativas IGC, ENADE e CAPES e como variáveis ilustrativas IES, Região, UF, Tipo e Nível. 
A partir do gráfico 7, é possível perceber, além da similitude existente entre os nível de avaliação dos cursos de administração, que as IES pertencentes aos Estados do ES e RS com IGC mais próximo de 4 possuem relação com IES federais e que oferecem cursos de pósgraduação em mestrado acadêmico e profissional e doutorado.

Além disso, por meio dos pontos que identificam os indivíduos, ou seja, cada IES analisada, é possível reconhecer as similitudes existentes com outras instituições. Por exemplo, a Univali, que, apesar de possuir as características abaixo, possui semelhanças com as IES municipais, IES do Estado de São Paulo, assim como se encontra distante das que, pelos índices, poderiam se considerar referências como as IES do Estado do Rio Grande do Sul, federais e aquelas que possuem cursos de pós-graduação dos três tipos existentes, conforme padrões da CAPES.

\begin{tabular}{|l|l|l|l|l|c|c|l|l|}
\hline Nome & IES & UF & Região & Tipo & IGC & ENADE & Nível & CAPES \\
\hline Univali & Univ & SC & Sul & PRIVADA & 3 & E-3 & Md & C-4 \\
\hline
\end{tabular}

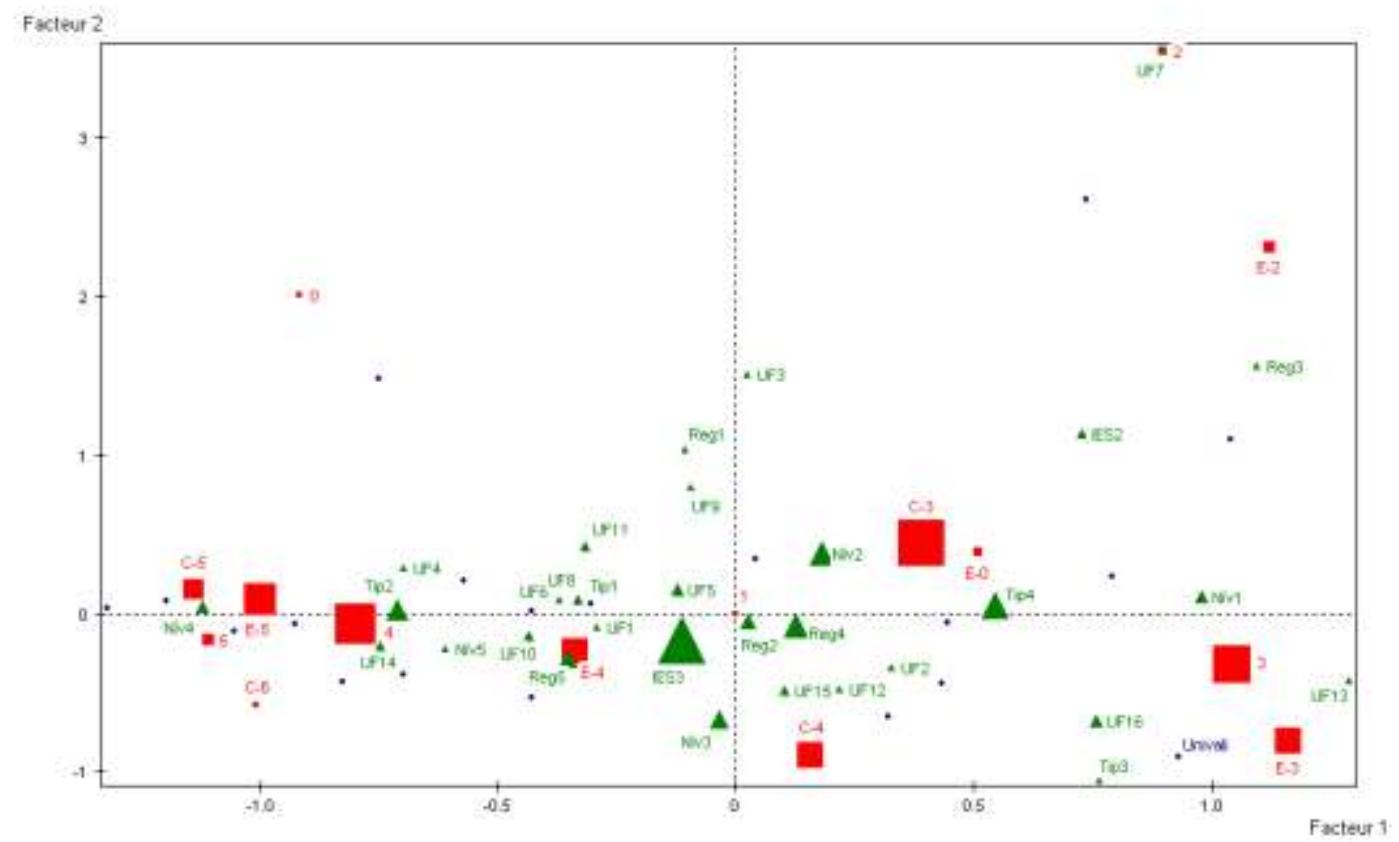

Gráfico 7: Cruzamento IGC, ENADE, CAPES x IES, Região, UF, Tipo e Nível Fonte: Gerados a partir do dados tratados no SPAD (2009)

\section{CONCLUSÃO}

A realização deste estudo proporcionou a possibilidade de uma avaliação que permita relacionar o IGC das IES com seus respectivos cursos. Aliás, dados como esses poderão fornecer subsídios para que gestores possam delimitar suas ações no sentido de construção e melhorias, como também com foco na competitividade existente no meio acadêmico.

Apesar de haver certas críticas na academia sobre os índices, o interesse aqui não foi esse, mas sim visou explorar os dados para que se possa ter melhor aproximação com a realidade, mesmo que esta seja realizada por meio dos índices.

$\mathrm{O}$ estudo teve como objetivo avaliar a similitude existente entre os índices de avaliação IGC, ENADE e CAPES dos cursos de administração. Por meio da coleta e análise realizadas, pôde-se perceber sim uma similitude em relação aos cursos de administração tanto 
em nível de graduação como de pós-graduação, pois corroboraram com suas alta notas do ENADE (E-4 e E-5), mais a CAPES (C-4, C-5) em direção aos IGC (4 e 5).

Também foram realizados outros cruzamentos adotando variáveis não ativas (ilustrativas) como IES, constatando-se a forte presença de universidades que obtiveram os maiores índices em todos os que foram analisados. Também foi possível perceber que as IES que oferecem cursos em nível stricto sensu, mais especificamente nas três modalidades (mestrado profissional, mestrado acadêmico e doutorado), são as que possuem IGC's mais altos, principalmente às de caráter federal. As regiões que acompanharam os índices mais altos foram Sul e Sudeste, com destaque para o Estado do Rio Grande do Sul. Por outro lado, na área da administração, demonstrou-se com maior carência, das IES analisadas, a região Norte.

Vale ressaltar que este trabalho sofreu limitações devido à não-incidência de IES que possuíam os resultados do ENADE e da CAPES, mas que não constavam na Tabela do IGC disponibilizada no sítio do INEP (2009). Destes outliers perfazem um total de 11 IES não analisadas.

Sugere-se que mais estudos com a inclusão de outros índices possam ser pesquisados e relacionados ao IGC, assim como a realização da mesma metodologia com cursos de outras áreas do conhecimento, para que possam trazer melhorias e atuar de maneira competitiva.

\section{REFERÊNCIAS}

BARREYRO, G. B. De exames, rankings e mídia. Avaliação Revista da Educação Superior, Campinas, v. 13, n. 3, p. 863-868, nov. 2008.

BRASIL. Portaria Normativa n. 11, de 14 de abril de 2003. Institui Comissão Especial de Avaliação.

Lei 10.861, de 14 de abril de 2004. Institui o Sistema Nacional de Avaliação da Educação Superior - SINAES. Diário Oficial [da] República Federativa do Brasil, Brasília, DF, 20 mar 1996c. Seção 1, p. 4686.

. Portaria Normativa n. 12, de 05 de setembro de 2008. Institui o Índice Geral de Cursos da Instituição de Educação Superior (IGC). 2008a.

CAPES. Critérios gerais de avaliação de programa de Pós-Graduação em administração, contabilidade e turismo. 2009. Disponível em: $<$ http//:www.capes.gov.br $>$. Acesso em 26 ago. 2009.

CÓRDOVA, R. A. A brisa dos anos cinqüenta: a origem da Capes. InfoCapes, v. 4, n. 2, abril, p. 7-19, 1996.

INEP. Nota técnica: cálculo do conceito preliminar de cursos de graduação. Brasília: MEC/INEP, 2009a. Disponível em: <http://www.inep.gov.br>. Acesso em: 27 ago. 2009.

Exame Nacional de Desempenho de Estudantes. Brasília: MEC/INEP, 2009b. Disponível em: <http://www.inep.gov.br>. Acesso em: 27 ago. 2009.

MEC. Organização da evolução superior. Brasília: MEC, 2004. Disponível em: $<$ http//portal.mec.gov.br>. Acesso em: 01 set 2009. 
NEVES, A. A. B. Mensagem de presidente: Capes 45 anos. InfoCapes. Boletim informativo da Capes. Brasília, v. 4, n. 2, 1996.

POLIDORI, Marlis Morosini. Políticas de avaliação da educação superior brasileira: provão, SINAES, IDD, CPC, IGC e... outros índices. Avaliação: Revista da Educação Superior, Campinas, v. 14, n. 2, p. 267-290, 2009.

SGUISSARDI, Valdemar. Regulação estatal x cultura de avaliação institucional? Avaliação: Revista da Educação Superior, Campinas, v. 13, n. 3, p. 857-862, Nov. 2008.

SOUZA, J. P. de.; PEREIRA, L. B. Pós-Graduação no Brasil: análise do processo de concentração. Acta Scientiarum, Maringá, v. 24, n. 1, p. 159-166, 2002.

\section{LISTA DE ACRÔNIMOS}

CAPES - Coordenação de Aperfeiçoamento de Pessoal de Nível Superior

CEA - Comissão Especial de Avaliação da Educação Superior

CNE - Conselho Nacional de Educação

CPC - Conceito Preliminar de Cursos

ENADE - Exame Nacional de Desempenho de Estudantes

IES - Instituição(ões) de Ensino Superior

IDD - Índice de Diferença de Desempenho

IGC - Índice Geral de Cursos

INEP - Instituto Nacional de Estudos e Pesquisas Educacionais Anísio Teixeira

PAIUB - Programa de Avaliação Institucional das Universidades Brasileiras

MEC - Ministério da Educação

$\mathrm{SESu}$ - Secretaria da Educação Superior

SINAES - Sistema de Ensino de Avaliação da Educação Superior

SNPG - Sistema Nacional de Pós-Graduação

UF - Unidade Federativa 